\title{
PENGARUH PEMBERIAN PAKAN RAGI METODE TETES DENGAN DOSIS YANG BERBEDA TERHADAP KEPADATAN Brachionus plicatilis
}

\author{
Anita Padang*, Rochman Subiyanto*, Marwa**, Fira Aditya** \\ *Staf Pengajar FPIK UNIDAR-Ambon, Email: anita.padang@yahoo.co.id \\ **Staf Balai Perikanan Budidaya Laut Ambon, Email: -
}

\begin{abstract}
ABSTRAK
Brachionus plicatilis merupakan jenis zooplankton yang berperan penting sebagai pakan hidup bagi berbagai jenis ikan yang dibudidayakan. Keunggulan Brachionus plicatilis sebagai pakan adalah ukurannya kecil (150$220 \mu \mathrm{m})$, berenang lambat sehingga mudah dimangsa oleh larva, waktu kultur relatif singkat, laju reproduksi tinggi, kandungan gizi cukup tinggi serta dapat diperkaya dengan asam lemak dan antibiotik. Ragi merupakan jenis pakan alternatif bagi Brachionus plicatilis yang umumnya digunakan apabila kultur fitoplankton tidak mencukupi. Penelitian ini bertujuan untuk mengetahui pengaruh dosis pakan ragi metode tetes yang terbaik untuk kepadatan Brachionus plicatilis. dan dilaksanakan pada bulan September 2014, di Balai Perikanan Budidaya Laut Ambon. Penelitian ini menggunakan RAL yang terdiri dari tiga perlakuan dosis ragi yaitu $A=0,3$ gram, $B=0,6$ gram dan $C=0,9$ gram dengan kepadatan awal Brachionus plicatilis sebanyak 50 ind/ml setiap perlakuan. Setiap perlakuan dilakukan sebanyak tiga kali ulangan. Hasil penelitian mendapatkan puncak kepadatan Brachionus plicatilis terjadi pada hari kedelapan yaitu dosis 0,9 gram dengan kepadatan sebesar $102 \mathrm{ind} / \mathrm{ml}$, dosis 0,6 gram dengan kepadatan $52 \mathrm{ind} / \mathrm{ml}$ dan dosis 0,3 gram dengan kepadatan 29 ind/ml. Analisa statistik mendapatkan dosis ragi 0,9 gram memberikan pertumbuhan yang lebih baik bagi Brachionus plicatilis. Parameter lingkungan mendukung pertumbuhan Brachionus plicatilis.
\end{abstract}

Kata Kunci : Pakan Ragi, Metode Tetes, Brachionus plicatilis

\section{PENDAHULUAN}

Pembenihan ikan laut merupakan mata rantai pertama dari usaha pengembangan budidaya ikan laut. Keberhasilan produksi benih ikan laut baik dari segi kuantitas maupun kualitas sangat dipengaruhi oleh keberhasilan penyediaan pakan dan manajemen pakan untuk larva ikan laut secara tepat dan effisien.

Brachionus plicatilis merupakan organisme dari golongan zooplankton yang mempunyai peran penting sebagai pakan hidup bagi berbagai jenis ikan yang dibudidayakan. Menurut Sulkin dan Epifanio (1975) dalam Christiansen dan Yang (1976)
Brachionus plicalitis mampu memberikan kelangsungan hidup yang lebih tinggi pada larva kepiting sampai fase zoea III dan secara nyata mempercepat proses molting ke fase zoea II. Selanjutnya Ghufran (2007) mengemukakan bahwa Brachionus plicatilis merupakan pakan yang baik untuk larva ikan kerapu macan (Epinephelus fuscoguttatus).

\section{Brachionus plicatilis}

merupakan salah satu jenis rotifer yang digunakan secara luas sebagai pakan larva ikan laut. Bahkan selama hampir empat periode terakhir Brachionus plicatilis digunakan sebagai pakan awal dalam pemeliharaan larva ikan laut seperti pada 
kakap putih (Lates calcalifer), belanak (Mugil cephalus) dan lain sebagainya (FAO, 1998 dalam Lubzens dan Zmora, 2003).

Keunggulan Brachionus plicalitis sebagai pakan adalah ukurannya kecil (150-220 um) dan berenang lambat sehingga mudah dimangsa oleh larva (Rusdi, 1997), waktu kultur yang relatif singkat dan mempunyai laju reproduksi yang tinggi (Giliberto and Mazzola 1981), berukuran kecil, berenang lambat sehingga mudah dimangsa oleh larva, mudah dicerna, mudah dikembangbiakkan, mempunyai kandungan gizi yang cukup tinggi serta dapat diperkaya dengan asam lemak dan antibiotik (Lubzens et al., 1989).

Ragi merupakan jenis pakan alternatif bagi Brachionus plicatilis yang umumnya digunakan apabila kultur fitoplankton tidak mencukupi. Satu gram ragi diprediksi dapat menghasilkan sekitar $\mathbf{8 0 . 0 0 0}$ Brachionus plicatilis (Hirano 1987 dalam Lubzens dan Zmora 2003).

Selanjutnya Frank dan Terry (1987) mengemukakan bahwa ragi roti basah biasanya digunakan dengan dosis 1-3 gram/ 10 juta individu rotifer dan ragi roti kering digunakan dengan dosis 0,3-0,9 gram/10 juta individu rotifer. Ragi roti merupakan salah satu pakan yang potensial dalam meningkatkan pertumbuhan Brachionus plicatilis. Ragi roti juga memiliki kandungan karbohidrat dan protein yang tinggi yang sangat baik bagi pertumbuhan Brachionus plicatilis (Roosharoe, 2006). Penggunaan ragi sebagai pakan rotifer dalam penerapannya relatif mudah dan ketersediannya cukup stabil di pasaran serta dapat disimpan lebih lama (Dheart, 1996; Sahandi dan Jafaryan, 2011).

Berbagai kegiatan penelitian dan pengembangan produksi Brachionus plicatilis dengan pemberian pakan ragi telah diupayakan, baik penggunaan pakan ragi roti, minyak ikan dan kuning telur (Waspada $d k k$, 1991), pemberian ragi, Chlorella sp dan Tetraselmis sp (Rachmasari, 1989) dan penggunaan ragi roti, scott's emulsion, Vitamin $B_{12}$ (Wati \& Imanto, 2009), Chlorella sp, ragi roti, vitamin $B_{12}$ dan vitamin $C$ (Chilmawati dan Suminto, 2010). Akan tetapi, metode yang dilakukan untuk pemberian pakannya yaitu dengan metode tebar yang frekuensi pemberian pakan dua kali dalam satu hari.

Kultur dengan menggunakan pakan ragi metode tetes dengan dosis yang berbeda memiliki kelebihan yaitu menghemat waktu dan tenaga dimana frekuensi pemberian pakan hanya satu kali dalam sehari. Penelitian Rumakat (2014) menemukan bahwa dengan menggunakan metode tetes ternyata memberikan kepadatan pertumbuhan Brachionus plicatilis sangat cepat.

Sehingga tujuan penelitian ini adalah mengetahui pengaruh dosis pakan ragi metode tetes yang terbaik untuk kepadatan Brachionus plicatilis. Penelitian ini diharapkan berguna sebagai bahan informasi bagi instansi terkait maupun masyarakat pembudidaya khususnya pembenihan ikan laut yang menggunakan pakan alami Brachionus plicatilis.

\section{METODOLOGI PENELITIAN}

\subsection{Waktu dan Lokasi Penelitian}

Penelitian ini dilaksanakan pada bulan September 2014 di Balai Perikanan Budidaya Laut Ambon (BPBLA).

\subsection{Prosedur Penelitian}

Penelitian diawali dengan persiapan alat dan bahan. Wadah kultur beserta seluruh peralatan kultur yang akan digunakan disterilkan dengan kaporit 10 ppm, kemudian diisi air laut steril sebanyak 40 liter. Selanjutnya media kultur yang berisi air kembali disterilkan lagi dengan kaporit 10 ppm dan dibiarkan selama 24 jam, yang bertujuan untuk menghilangkan organisme lain (bakteri). Tes kandungan kaporit dalam media dengan menggunakan klorin tes, dan aerator dijalankan untuk menyuplai oksigen ke dalam media kultur. Bibit Brachionus plicatilis ditebarkan ke dalam media kultur dengan kepadatan awal 50 ind $/ \mathrm{ml}$.

Penelitian ini menggunakan Rancangan Acak Lengkap (RAL) yang terdiri dari 3 perlakuan dan 3 kali ulangan setiap perlakuan yaitu : 1). Perlakuan A dengan dosis 0,3 gram ragi; 2). Perlakuan $B$ dengan dosis 0,6 gram ragi dan perlakuan $C$ dengan dosis 0,9 
gram ragi. Pakan ragi diberikan setiap hari dengan frekuensi pemberian satu kali dalam sehari dan diupayakan pakan tersebut habis selama 24 jam. perlakuan da

ragi yang diberikan semua ulangan sebanyak
25 gram/5 liter air laut steril dengan metode tetes yang diatur kecepatan tetesnya yaitu $4,8 \mathrm{jam} / 1$ atau $17,3 \mathrm{detik} / \mathrm{ml}$. Cara pemberian ragi roti dengan metode tetes dapat dilihat pada Gambar 1.
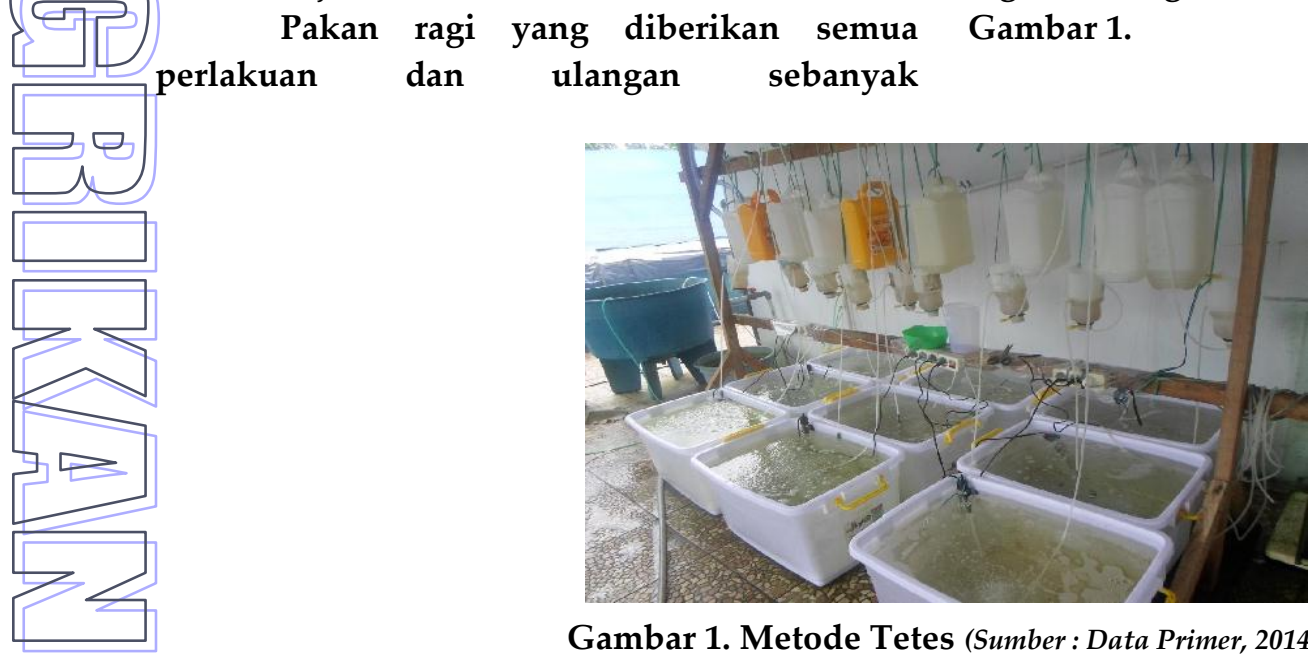

Gambar 1. Metode Tetes (Sumber: Data Primer, 2014)

Sampel Brachionus plicatilis diambil setiap 24 jam selama 14 hari, dengan pipet tetes kemudian dimasukkan ke dalam botol sampel. Dilanjutkan dengan pemberian formalin 10\% sebanyak 3 tetes yang bertujuan agar pada saat diidentifikasi Brachionus plicatilis tidak bergerak. Pengamatan kepadatan Brachionus plicatilis menggunakan haemocytometer dan mikroskop NIKON SF pembesaran 200X sebanyak 3 kali ulangan. Pengukuran parameter lingkungan meliputi suhu, pH dan salinitas.

\subsection{Analisis Data}

Analisis data pertumbuhan Brachionus plicatilis meliputi :

a. Kepadatan

Kepadatannya dihitung berdasarkan formula menurut Isnansetyo dan Kurniastuty (1995) :

$$
\mathrm{N}=\text { ind } / \mathrm{ml}
$$

Dimana : $\mathbf{N}$ adalah jumlah Brachionus plicatilis yang dihitung dalam $1 \mathrm{ml}$ air pada sel sedwich b. Analisa Statistik

Guna menguji hipotesis adanya pengaruh dosis ragi metode tetes terhadap pertumbuhan Brachionus plicatilis digunakan analisis statistik One-Way Analisis Of Variance (One-Way ANOVA) menurut Zar (1999) yang diolah dengan program Microsoft Excel.

\section{HASIL DAN PEMBAHASAN}

3.1. Kepadatan Brachionus plicatilis

Berdasarkan hasil pengamatan kepadatan Brachionus plicatilis yang dilakukan selama penelitian diperoleh kepadatan ratarata yang berbeda dari masing-masing perlakuan selama 14 hari kultur, dapat dilihat pada Tabel 1.

Tabel 1. Kepadatan Rata-Rata Brachionus plicatilis (ind $/ \mathrm{ml}$ )

\begin{tabular}{|c|c|c|c|}
\hline \multirow{2}{*}{ Hari } & \multicolumn{3}{|c|}{ Kepadatan Brachionus plicatilis (ind/ml) } \\
\cline { 2 - 4 } & Dosis 0,3 gram & Dosis 0,6 gram & Dosis 0,9 gram \\
\hline 0 & 50 & 50 & 50 \\
\hline 1 & 15 & 15 & 24 \\
\hline 2 & 12 & 14 & 29 \\
\hline 3 & 17 & 20 & 29 \\
\hline 4 & 16 & 30 & 47 \\
\hline 5 & 20 & 38 & 73 \\
\hline 6 & 18 & 41 & 70 \\
\hline 7 & 22 & 44 & 87 \\
\hline 8 & 29 & 52 & 102 \\
\hline 9 & 26 & 37 & 79 \\
\hline 10 & 25 & 34 & 55 \\
\hline 11 & 17 & 28 & 48 \\
\hline 12 & 14 & 25 & 43 \\
\hline 13 & 11 & 24 & 42 \\
\hline 14 & 7 & 19 & 36 \\
\hline
\end{tabular}

Sumber : Data Primer 2014 
Tabel 1 dan Gambar 2, memperlihatkan bahwa pada hari pertama kultur kepadatan Brachionus plicatilis mengalami penurunan, hal ini disebabkan karena pada hari pertama kultur Brachionus plicatilis masih mengalami fase adaptasi. Sebagaimana pernyataan Isnansetyo dan Kurniastuty (1995) bahwa pada fase ini Brachionus plicatilis masih menyesuaikan diri dengan lingkungan baru atau dengan media kultur sehingga belum menunjukkan penambahan kepadatan.

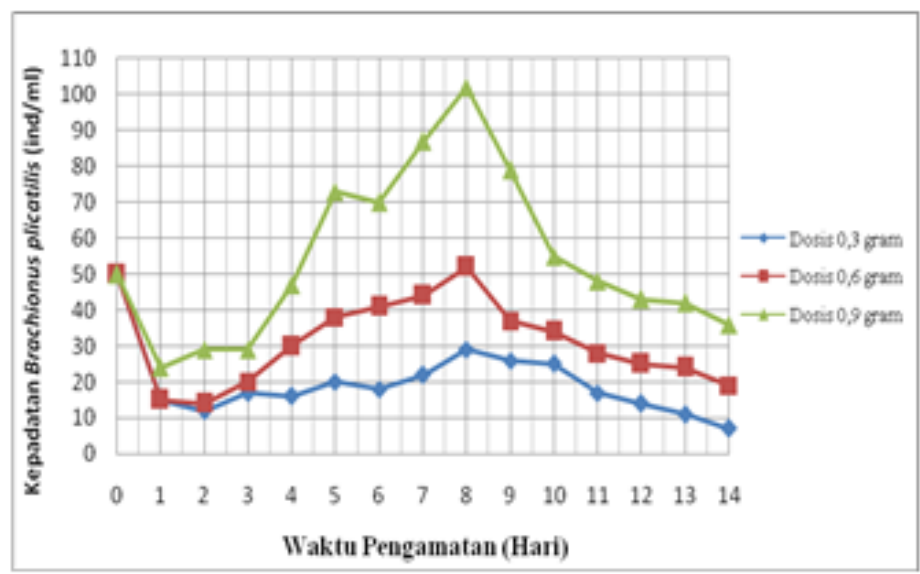

Gambar 2. Grafik Pertumbuhan Brachionus plicatilis (Sumber : Data Primer, 2014)

Penelitian ini mendapatkan bahwa ketiga perlakuan mengalami pertumbuhan Brachionus plicatilis yang lambat dimana proses adaptasinya hingga hari keempat, kemudian pada hari kelima terjadi perubahan jumlah individu. Perubahan terus terjadi pada ketiga perlakuan, pada perlakuan dosis terjadi pengurangan jumlah individu berbeda dengan perlakuan dosis 0,9 gram yang menggalami penambahan.

Puncak kepadatan Brachionus plicatilis terjadi pada hari kedelapan pada dosis 0,6 sebanyak 52 ind $/ \mathrm{ml}$ dan 0,9 gram sebanyak $102 \mathrm{ind} / \mathrm{ml}$ (tabel 1), sedangkan dosis 0,3 gram sebanyak 29 ind $/ \mathrm{ml}$, kepadatannya lebih rendah dari jumlah bibit awal. Puncak pertumbuhan Brachionus plicatilis terjadi pada hari kedelapan, sebagaimana pernyataan Isnansetyo dan Kurniastuty (1995) bahwa kepadatan Brachionus plicatilis mencapai puncak pada hari ketujuh dan kedelapan. Selanjutnya pada hari kesembilan terjadi penurunan sampai pada akhir penelitian yang memperlihatkan fase kematian.

Gambar

2 memperlihatkan perlakuan ragi roti dosis 0,3 gram memiliki kepadatan Brachionus plicatilis yang rendah dibandingkan dengan perlakuan dosis 0,6 dan dosis 0,9 gram. Hal ini dikarenakan dosis pakan lebih sedikit dibandingkan dengan perlakuan dosis 0,6 dan dosis 0,9 gram, sehingga tidak terpenuhi kebutuhan nutrisi yang dibutuhkan bagi pertumbuhan Brachionus plicatilis. Sebagaimana dikemukakan Rina et al (2012) bahwa frekuensi pemberian dosis pakan juga berpengaruh terhadap pertumbuhan dan laju reproduksi. Sedangkan pada perlakuan dosis 0,6 dan 0,9 gram memberikan nutrisi yang cukup hingga berpengaruh pada kepadataan Brachionus plicatilis terutama pada perlakuan dosis 0,9 gram.

Setelah mencapai kepadatan maksimal pada hari kedelapan sebaiknya dipanen karena pada hari berikutnya Brachionus plicatilis akan mengalami penurunan kepadatan, yaitu dosis 0,9 gram menjadi 79 ind $/ \mathrm{ml}, 0,6$ gram menjadi $37 \mathrm{ind} / \mathrm{ml}$ dan dosis 0,3 gram menjadi $26 \mathrm{ind} / \mathrm{ml}$. Hal ini diperkuat oleh pernyataan Guhfran (2007) bahwa pertumbuhan Brachionus plicatilis pada umumnya menunjukkan pola yang sama dengan pola pertumbuhan zooplankton pada umumnya yaitu mengalami empat fase pertumbuhan yaitu fase adaptasi, fase pertumbuhan, fase penurunan dan fase 
kematian.

Penelitian ini mendapatkan ragi dengan dosis rendah memberikan kepadatan Brachionus plicatilis yang rendah. Hal ini diasumsikan bahwa ragi memberikan nutrisi yang kurang bagi pertumbuhan Brachionus plicatilis. S ebagaimana pernyataan Hirayama dan Stuito (1991) dalam Chilmawati dan Suminto (2010) bahwa ragi roti nilai nutrisnya rendah, Imada (1980) dalam Chilmawati dan Suminto (2010) bahwa ragi roti mengandung 3\% Omega-3 HUFA lebih rendah dibanding Chlorella sp yaitu $29 \%$. Selanjutnya juga diperkuat oleh pernyataan Redjeki et al (1993) bahwa dalam pemberian ragi roti sebaiknya ditambahkan berbagai macam

Tabel 2. Hasil One Way ANOVA Kepadatan Brachionus plicalitis

\begin{tabular}{|c|c|c|c|c|c|c|}
\hline \multirow{2}{*}{ SK } & \multirow{2}{*}{ Db } & \multirow{2}{*}{$\mathbf{J K}$} & \multirow{2}{*}{$\mathbf{K T}$} & \multirow{2}{*}{ F hitung } & \multicolumn{2}{|c|}{ F tabel } \\
\hline & & & & & $5 \%$ & $1 \%$ \\
\hline Pelakuan & 2 & 1875.088 & 937.5442 & & & \\
\hline Galat & 6 & 840.717 & 140.1195 & 6.691033 & 5.143253 & 10.92477 \\
\hline Total & 8 & 2715.805 & & & & \\
\hline
\end{tabular}

Hasil uji ANOVA pada tabel di atas menunjukkan bahwa penggunaan dosis pakan ragi yang berbeda dengan metode tetes ternyata memberikan pengaruh secara signifikan terhadap kepadatan Brachionus

plicatilis pada tingkat kepercayaan $95 \%$. Hasil uji lanjut menggunakan uji BNT memperlihatkan perbedaan nilai rata-rata setiap perlakuan dan dapat dilihat pada Tabel 3.

Tabel 3. Hasil Uji Lanjut Pengaruh Dosis Pakan Ragi Dengan Metode Tetes Terhadap Kepadatan Brachionus plicatilis

\begin{tabular}{lcc}
\hline \multicolumn{1}{c}{ Perlakuan } & Rata-Rata & Nilai \\
\hline Dosis 0.3 Gr & 20.29 & $\mathrm{a}$ \\
Dosis 0.6 Gr & 31.82 & $\mathrm{ab}$ \\
Dosis $0.9 \mathrm{Gr}$ & 55.00 & $\mathrm{~b}$ \\
\hline BNT 5\% $=23.690$ & & \\
Sumber : Data Primer 2014 & &
\end{tabular}

Hasil uji lanjut BNT mendapatkan pada tingkat kepercayaan $95 \%$, ragi dengan dosis 0,9 gram lebih berpengaruh terhadap pertumbuhan Brachionus plicatilis dibandingkan dosis 0,3 gram dan 0,6 gram. Ternyata ragi dengan dosis yang lebih besar menghasilkan kepadatan Brachionus plicatilis yang lebih tinggi. Hal yang sama juga ditemukan oleh Iksan $d k k$ (2015) yaitu ragi dengan dosis $30 \mathrm{mg} / 1$ memberikan kepadatan populasi tertinggi bagi Brachionus plicatilis dibandingkan dosis $7,5 \mathrm{mg} / 1,15,0 \mathrm{mg} / 1$ dan 22,5 $\mathrm{mg} / \mathrm{l}$.

\subsection{Parameter Lingkungan}

A. Suhu

Suhu merupakan salah satu faktor penentu dalam pertumbuhan Brachionus plicatilis. Pada umumnya perubahan suhu air di alam terbuka dipengaruhi oleh intensitas cahaya. Fulks dan Main (1991) mengemukakan bahwa kisaran suhu air yang baik untuk 
pertumbuhan Brachionus plicatilis adalah 20$30^{\circ} \mathrm{C}$, sedangkan untuk reproduksi berkisar antara $30-34^{\circ} \mathrm{C}$. Pernyataan yang lain tentang suhu bagi Brachionus plicatilis yaitu Isnansetyo dan Kurniastuty (1995) mengemukakan bahwa kisaran suhu optimum untuk pertumbuhan dan reproduksi Brachionus plicatilis adalah sebesar $22-30^{\circ} \mathrm{C}$. Suhu air selama proses penelitian adalah sebesar $29^{\circ} \mathrm{C}$, berarti suhu yang ditemukan mendukung pertumbuhan dan reproduksi Brachionus plicatilis.

B. $\mathrm{pH}$

pH adalah ukuran dari konsentrasi ion hidrogen dan dapat menunjukkan suasana air tersebut apakah asam atau basa (Boyd, 1982). pH secara tidak langsung mempengaruhi pertumbuhan populasi rotifer, tergantung dari jenis makanan yang diberikan dan dapat mempengaruhi jumlah amoniak bebas (Yu dan Hirayama, 1986).

pH turut mempengaruhi kehidupan Brachionus plicatilis. Brachionus plicatilis masih dapat bertahan hidup pada $\mathrm{pH}$ 5-10, sedangkan $\mathrm{pH}$ optimum untuk pertumbuhan dan reproduksinya berkisar antara 7,5-8,0 (Isnansetyo dan Kurniastuty, 1995), pH optimum antara 5-9 (Fukusho, 1989 dalam Redjeki (1999), 6,5-8,5 (Fulks dan Main, 1991). pH wadah kultur selama penelitian sebesar 8,5. Sedangkan penelitian Novita $d k k$ (2017)mendapatkan pH wadah kultur Brachionus plicatilis sebesar 7,3-9,7. Dengan demikan pH wadah kultur masih dalam kisaran $\mathrm{pH}$ optimum bagi pertumbuhan Brachionus plicatilis.

C.Salinitas

Brachionus plicatilis bersifat euryhalin.
Menurut Redjeki (1999) Rotifer dapat mentolerir salinitas dengan kisaran 1-60 ppt tetapi salinitas terbaik untuk pertumbuhannya antara 10-20 ppt. Sedangkan Isnansetyo dan Kurniastuty (1995) mengemukakan bahwa betina dengan telurnya dapat bertahan hidup pada salinitas $38 \%$, sedangkan salinitas optimum adalah 10-35\%.

Jika terjadi perubahan salinitas yang besar dalam waktu yang singkat maka Brachionus plicatilis akan stress dan aktifitas berenangnya terhenti (Lubzens et al., 1989; Hoff \& Snell dalam Fulks \& Main, 1991). Salinitas wadah kultur Brachionus plicatilis selama penelitian sebesar $34 \%$, berarti salinitas juga mendukung pertumbuhan Brachionus plicatilis.

\section{PENUTUP}

\subsection{Kesimpulan}

Berdasarkan hasil penelitian, dapat disimpulkan sebagai berikut:

1. Puncak kepadatan Brachionus plicatilis tertinggi terjadi pada hari kedelapan yaitu dosis 0,9 gram dengan kepadatan $102 \mathrm{ind} / \mathrm{ml}$, dosis 0,6 gram dengan kepadatan 52 ind $/ \mathrm{ml}$ dan dosis 0,3 gram dengan kepadatan 29 ind $/ \mathrm{ml}$.

2. Dosis 0,9 gram lebih berpengaruh pada pertumbuhan Brachionus plicatilis.

3. Parameter lingkungan selama penelitian mendukung pertumbuhan dan reproduksi Brachionus plicatilis.

\subsection{Saran}

Diharapkan adanya penelitian lanjutan tentang pemberian pakan ragi dengan dosis 0,9 gram menggunakan metode tetes dengan menambahkan nutrisi tambahan selain ragi.

\section{DAFTAR PUSTAKA}

Boyd C.E. 1982. Water quality management for fish culture. Elsevier. Science publishers B.V. Amsterdam : 318 pp

Chilmawati, D dan Suminto. 2009.Pengaruh Penggunaan Ragi Roti, Vitamin $B_{12}$ dan

Vitamin C Sebagai Bahan Pengkaya Pakan Terhadap Pertambahan Populasi Brachionus plicatilis. Jurnal Saintek Perikanan Vol. 5, No. 2, 2010 : 47 - 53

Christiansen, M.E. and W.T. Yang. 1976. Feeding Experiment on the Larva of Fiddler Crab Uca pugilatot (Brachyura, Ocypodidae), Reared in the Hatchery. Aquaculture, 8:91-98.

Dhert, P. 1996. Rotifers. In : P. Lavens and

P. Sorgeloos (ed). Manual on the production and use of live food for

aquaculture. FAO Fisheries Technical 


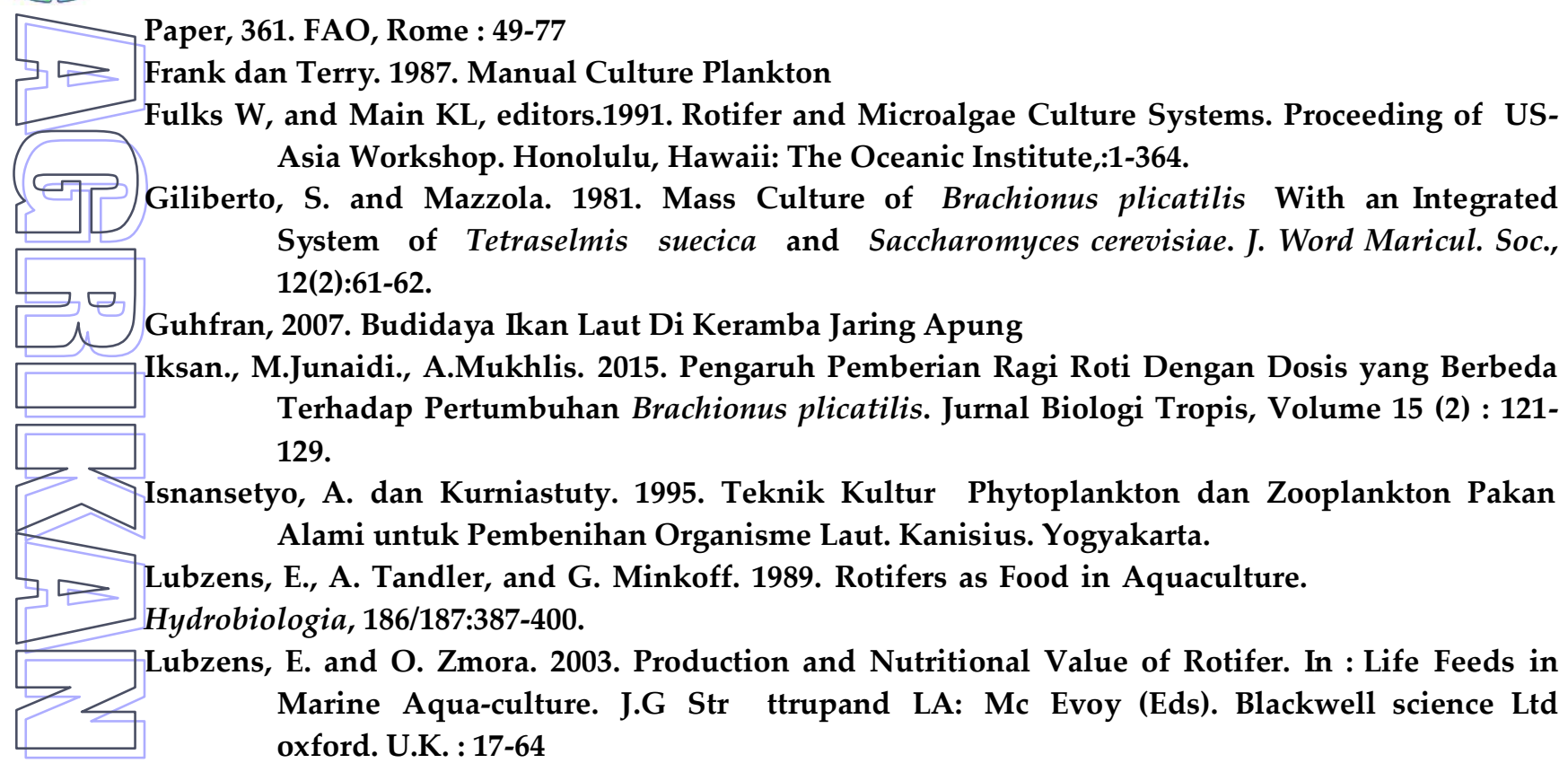

Novita, N., S.Karina., N.Nurfadillah. 2017. Pengaruh Pemberian Dedak Padi Hasil Fermentasi Ragi (Saccharomyces cerevisiae) Terhadap Pertumbuhan Rotifera (Brachionus plicatilis). Jurnal Ilmiah Mahasiswa Kelautan dan Perikanan Unsyiah, Volume 2, Nomor 2 : 268-276

Rachmasari, M. 1989. Studi Pertumbuhan Rotifer Brachionus plicatilis dengan Pakan Chlorella sp, Tetraselmis dan Ragi Roti. Skripsi. Fakultas Perikanan, Institut Pertanian Bogor. 72 hlm.

Redjeki S., R. Purba dan P.T. Evianto 1993. Pengkayaan Rotifer untuk Meningkatkan Pertumbuhan dan Kelangsungan Hidup Larva Kakap Putih Lates calcarifer. Jur. Pen. Bud. Pantai 9 (5) : 65-75.

Redjeki, S.1999. Budidaya Rotifer (Brachionus plicatilis). Oseano Volume XXIV Nomor 2 :27-43

Rina P. Astuti, Sophia L. Sagala, Gunawan, Gede S. Sumiarsa, dan Philip T. Imanto.

2012. Optimasi Dosis Dan Frekuensi Pakan Dalam Produksi Rotifer (Brachionus rotundiformis). J.Ilmu dan Teknologi Kelautan Tropis, Vol. 4, No. 2, Hlm. 239-246.

Roosharoe, I. 2006. Mikologi Dasar Dan Terapan Yayasan Obor Indonesia, Jakarta.Hlm. 56-64

Rumakat, A.F.P. 2014. Laporan Praktek Kerja Lapangan. Teknik Kultur Brachionus plicatilis dengan Pemberian Ragi Metode Tetes. Fakultas Perikanan Universitas Darussalam Ambon.

Rusdi, I. 1997. Pertumbuhan Populasi Rotifer (Brachionus rotundiformis) Type-S Pada Suhu Yang Berbeda di Laboratorium. J. Penelitian Perikanan Indonesia, 3(4):62-66.

Sahandi, J., and H. Jafaryan. 2011. Rotifer (Brachionus plicatilis) culture inbatch system with suspension of algae (Nannochloropsis oculata) and bakery

Yeast (Saccharomyces cerevisiae). AACL Bioflux, 4(4) : 526-529

Waspada, Mayunar, dan T. Fatoni. 1991. Upaya Peningkatan Gizi Rotifer Brachionus plicatilis Untuk Menunjang Keberhasilan Pembenihan Kerapu Macan E. Fuscoguttatus. J. Penel. Budidaya Pantai, 7(2):73-80.

Wati, M. dan P.T. Imanto. 2009. Kultur Rotifer Dengan Beberapa Jenis Pakan dan Kombinasinya. J. Riset Aquakultur, 4(3):349-359

Yu J.P. and K. Hirayama. 1986. The Effect of un-ionized Ammonia on the Population Growth of the Rotifer, Brachionus pticatilis in Mass Culture. Bull. Japan, Soc. Sci. Fish 52 (9) : 1509-1513.

Zar, J.H.1999. Biostatical Analysis $4^{\text {th }}$ Edition. Simon and Schuter An Viacom Company, USA pp 616. 